\title{
Uterine cervix and proximal third of vagina agenesis with functional uterus: Case report and literature review
}

\author{
Ana Luíza Fonseca Siqueira', Marta Ribeiro Hentschke1, Martina Wagner', Luiza Machado Kobe ${ }^{1}$, \\ Charles Schneider Borges ${ }^{1}$, Vanessa Devens Trindade ${ }^{1}$, Marcelo Moretto ${ }^{1}$, Andrey Cechin Boeno ${ }^{1}$, \\ Adriana Arent $^{1}$
}

1Pontifícia Universidade Católica do Rio Grande do Sul, Hospital São Lucas, Serviço de Ginecologia, Porto Alegre, RS, Brasil

\begin{abstract}
Objectives: We aimed to describe the case of a patient presenting cervix agenesis with presence of vagina and functioning uterus. Methods: A 19-year-old patient was referred to Human Reproduction service due to primary amenorrhea, cyclic pelvic pain, and dyspareunia. She was diagnosed with cervical and vaginal agenesis, and menstrual flow suppression was the chosen treatment. Results: Regarding treatment options, hysterectomy is the classic treatment; however, due to advances in minimally invasive surgery and reproductive medicine, procedures such as uterine-vaginal anastomosis have been proposed. Young patients with no current reproductive wish, may opt for hormonal suppression of the menstrual flow to minimize cyclical discomfort and prevent or treat possible foci of endometriosis. However, for those seeking pregnancy, techniques of assisted reproduction can be considered. The approach should always be individualized, considering the anatomical details, clinical aspects, and patient's opinion. Conclusions: Management of cervical agenesis is a challenge due to the complexity of the malformation and the difficulty in restoring and preserving fertility. Lastly, report such rare conditions and its treatment options, seems to be beneficial to help other patients with similar conditions.
\end{abstract}

Keywords: congenital abnormalities; mullerian ducts; assisted reproduction.

\section{Introduction}

Primary amenorrhea has several anatomical and hormonal causes. Among the anatomical causes, several may be due to Mullerian malformations. ${ }^{1}$ In normal Mullerian development, there seems to be an orderly progression of uterus, uterine tubes, and vagina embryonic development. A change in this process results in congenital uterine anomalies. Mullerian malformations represent a set of structural abnormalities that may arise from the Mullerian ducts fusion failure in the midline, from an imperfect connection with the urogenital sinus, or from a defect in the light formation of the upper portion of vagina, and uterus, by inadequate absorption of cells from the central vagina and the septum between the molten Mullerian ducts. ${ }^{2}$ However, the actual cause of these anomalies is not clearly understood. It is estimated that Mullerian anomalies affect approximately $1 \%$ to $6 \%$ of women. Nevertheless, the exact incidence of these malformations is uncertain, since most data are the result of studies regarding obstetric complications or infertility. 2,3

Several classifications have been proposed for congenital uterine anomalies, based on the understanding of Müllerian system embryology, being the most used the one suggested by Buttram and Gibbons, ${ }^{4}$ later modified by the American Fertility Society (AFS).

Cervical agenesis is classified as a Mullerian anomaly type IB according to AFS classification, and results from an abnormal fusion of the Muller ducts with the urogenital sinus, or by the atrophy of a segment normally formed by the Müllerian system.

Financial support: None.

Conflict of interest: The authors declare no conflicts of interest.

Data de recebimento: $15 / 08 / 2019$

Data de aceite: $27 / 05 / 2020$

The study was carried out at Hospital São Lucas; Pontifícia Universidade Católica do Rio Grande do Sul, Porto Alegre, RS, Brasil.

Copyright Siqueira et al. This is an Open Access article distributed under the terms of the Creative Commons Attribution License, which permits unrestricted use, distribution, and reproduction in any medium, provided the original work is properly cited. 
Agenesis of the uterine cervix is a rare congenital defect, with a prevalence estimated as one in 80,000 women. ${ }^{5}$ The occurrence of cervical agenesis with the presence of vagina and functioning uterus is even rarer. It is estimated that only $4.8 \%$ of those patients with cervical agenesis have a functioning uterus.

Thus, the objective of this study was to report the case of a patient in whom such pathology was diagnosed and to discuss its management, through a review of the literature.

\section{Case description}

A 19-year-old female patient was seen at the gynecology outpatient clinic of São Lucas Hospital/PUCRS (Porto Alegre, Brazil) due to primary amenorrhea, cyclic pelvic pain, and dyspareunia. She had been previously tested for withdrawal bleeding with cyclic contraceptives for three months in another gynecology service, that was negative. She denied chronic diseases, current use of tobacco or illicit drugs. There was no family history of primary amenorrhea and no diethylstilbestrol exposure was reported by her mother. At the physical examination, the patient had $22 \mathrm{~kg} / \mathrm{m}^{2}$ body mass index (BMI), adequate secondary sexual characters development (Tanner Stage 5 breast and pubic hair development), and normal external genitalia. The speculum examination showed a five centimeters long vaginal canal and absence of the uterine cervix, which was confirmed by bimanual pelvic examination. The transvaginal ultrasound showed a uterus measuring $5.2 \times 4.1 \times 2.7 \mathrm{~cm}$ (30 cm $\mathrm{cm}^{3}$ volume) with absence of cervix caudal portion. The ovaries showed usual appearance. A complementary pelvic nuclear magnetic resonance imaging (MRI), with endovaginal gel, was performed. The MRI showed a single uterine body, with habitual shape. Both ovaries were normal. It was observed only the distal segment of the vagina, measuring $3.5 \mathrm{~cm}$ in length. The proximal two-thirds of the vagina and uterine cervix were not identified (Figure 1). Hormonal blood analysis revealed a follicle-stimulating hormone of $4,1 \mathrm{mUl} / \mathrm{mL}$ and estradiol of $60,3 \mathrm{pg} / \mathrm{mL}$, normal for patient's age. With these data, a diagnosis of cervical-vaginal agenesis was warranted. The patient and her family were informed about the diagnosis, and the treatment options were discussed. Considering the patient's future reproductive wish, continuous combined oral contraceptive therapy was started. Also, orientations regarding options for her reproductive future, were given. Currently, the patient is without cyclical pelvic pain, adherent to the proposed treatment and in periodic follow-up with the gynecology team.

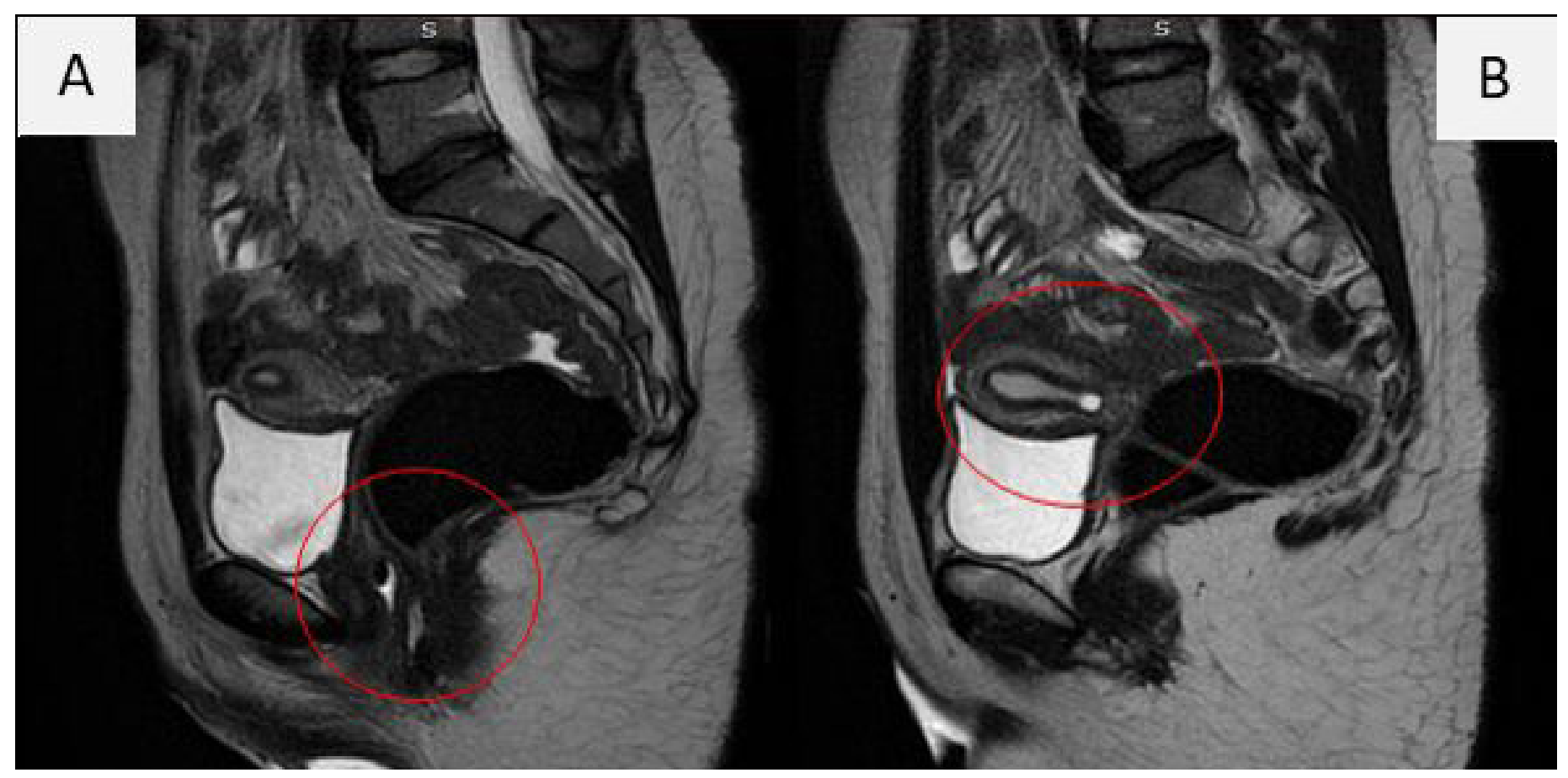

Figure 1. (A) Distal segment of the vagina. It was observed only the distal segment of the vagina, measuring $3.5 \mathrm{~cm}$ in length. The proximal two-thirds of the vagina and uterine cervix were absent; (B) Uterine body. A single uterine body with habitual shape was identified. Both ovaries were normal. 


\section{Discussion}

We reported a case of proximal two-thirds of vagina and uterine cervix agenesis, with functioning uterus, clinically presented as primary amenorrhea and cyclic pelvic pain due to cryptomenorrhea. Primary amenorrhea is defined as the absence of menses at age of 15 years old, in the presence of normal growth and secondary sexual characteristics. In general, primary amenorrhea is due to a genetic or anatomical abnormality, with Mullerian agenesis contributing to $15 \%$ of the causes. ${ }^{6}$ In face of primary amenorrhea, a complete evaluation is necessary to identify the cause. ${ }^{7}$ The uterine cervix is important for the exit of menstrual blood, and its agenesis or dysgenesis can lead to a retrograde flow. This blockade of menstrual flow can cause hematometra, hematosalpinx, endometriosis and also pelvic infection if the diagnosis is delayed. ${ }^{8}$ This congenital defect is usually diagnosed when the patient seeks care for primary amenorrhea, cyclical or chronic pelvic pain, dyspareunia, and eventually a pelvic mass (hematometra). The treatment aims to treat the symptoms, to avoid complications and to preserve fertility in those patients with functioning reproductive system.

Historically, the classic treatment was hysterectomy ${ }_{1}^{8}$ since the possibility of a viable pregnancy was unlikely. Currently, the treatment depends on patients' reproductive plans, considering the advances of medicine, especially with special regard to assisted reproduction techniques (ART).

The treatment of this malformation is still challenging. Several surgical techniques have been tried to promote uterovaginal channeling in patients with functioning uterus. However, complications such as peritonitis and the need for re-intervention were observed. ${ }^{9}$ The use of laparoscopic technique for uterovaginal anastomosis gained space and was successful in several cases, restoring normal menstrual flow without dysmenorrhea., $, 8,10-13$ Uterovaginal anastomosis with cervical and / or vaginal reconstruction using grafts (thin-skinned, full-skinned, bladder-mucosal, sigmoid-colon, and saphenous-vein) is one of the options for restoring normal menstrual flow. Currently, it is also possible to perform these procedures by robotic surgery. Four cases of uterovaginal anastomosis and a cervical-vaginal reconstruction with small intestinal mucosa, all with surgical success, have been reported. ${ }^{14,15}$

Clinical treatment can be an option if the patient does not manifest a current wish to get pregnant. It is based on the use of long-term medications that block menstruation. The most used are combined contraceptives (estrogen and progesterone), progesterone alone or gonadotrophin releasing hormone (GnRh) agonists with add-back therapy. This treatment, which avoids hematometra, dysmenorrhea and chronic pelvic pain, can be maintained until there is a wish to get pregnant, when the medications should be stopped, and ART should be used.

Some authors argue that classical management (hysterectomy) should be the first choice in order to avoid complications such as ascending infection and the need for reintervention due to stenosis. ${ }^{8,9}$ On the other hand, the new surgical techniques might be used as the first option, considering the maintenance of fertility. ${ }^{5}$

In vitro fertilization (IVF) followed by trans-myometrial embryo transfer may be an option for patients with cervicovaginal agenesis. The first trans-myometrial transfer was described by Parsons et al., in 1987. Later the technique was improved by Towako. ${ }^{16,17}$ By the Towako method, intrauterine embryo transfer is performed under ultrasonographic guidance, using an echogenic needle and a trans-myometrial approach to the endometrial border. ${ }^{17}$ There are five reports of pregnancy with fresh or frozen embryo transfers using this technique in patients with cervical agenesis, of which three have reached the end of gestation and two evolved to abortion. ${ }^{14,18-20}$ Transfer of embryos or gametes to the fallopian tube (ZIFT and GIFT) are optional techniques in cervical agenesis cases, but both require surgery, therefore increasing the risk of complications. However, a successful ZIFT case has been reported. ${ }^{21,22}$ In addition, a successful case of simultaneous trans-myometrial and fallopian embryo transfer with cesarean section due to preeclampsia at 32 weeks' gestation was also described. ${ }^{23}$

In summary, it was presented the case of a patient with cervical, upper and middle third of the vagina agenesis. It highlights the importance of thoroughly investigating patients with primary amenorrhea. This is a rare pathology, and the treatment options should be discussed and decided depending on patients complains and reproductive future wish. The patient's fertility future should always be considered, especially when the upper reproductive system is intact.

\section{Acknowledgements}

Coordenação de Aperfeiçoamento de Pessoal de Nivel Superior - Brasil (CAPES) - Finance Code 001. V.D.T and M.R.H are CAPES scholarship holders. We thank all the doctors and students that were clinically involved in this case.

\section{References}

1. The American Fertility Society. The American Fertility Society classifications of adnexal adhesions, distal tubal occlusion, tubal occlusion secondary to tubal ligation, tubal pregnancies, mullerian anomalies and intrauterine adhesions. Fertil Steril. 1988;49(6):944-55. http://dx.doi.org/10.1016/S0015-0282(16)59942-7. PMid:3371491. 
2. Acién P, Acien M, Sanchez-Ferrer M. Complex malformations of the female genital tract. New types and revision of classification. Hum Reprod. 2004;19(10):2377-84. http://dx.doi.org/10.1093/humrep/deh423. PMid:15333604.

3. McBean JH, Brumsted JR. Septate uterus with cervical duplication: a rare malformation. Fertil Steril. 1994;62(2):415-7. http:// dx.doi.org/10.1016/S0015-0282(16)56901-5. PMid:8034095.

4. Buttram VC Jr, Gibbons WE. Mullerian anomalies: a proposed classification. (An analysis of 144 cases). Fertil Steril. 1979;32(1):40-6. http://dx.doi.org/10.1016/S0015-0282(16)44114-2. PMid:456629.

5. Creighton SM, Davies MC, Cutner A. Laparoscopic management of cervical agenesis. Fertil Steril. 2006; 85(5):1510.

6. Reindollar RH, Byrd JR, McDonough PG. Delayed sexual development: A study of 252 patients. Am J Obstet Gynecol. 1981;140(4):37180. http://dx.doi.org/10.1016/0002-9378(81)90029-6. PMid:7246652.

7. Practice Committee of American Society for Reproductive Medicine. Current evaluation of amenorrhea. Fertil Steril. 2008;90(Suppl. 5):S219-25. http://dx.doi.org/10.1016/j.fertnstert.2008.08.038. PMid:19007635.

8. Rock JA, Schlaff WD, Zacur HA, Jones HW Jr. The clinical management of congenital absence of the uterine cervix. Int J Gynaecol Obstet. 1984;22(3):231-5. http://dx.doi.org/10.1016/0020-7292(84)90012-2. PMid:6148283.

9. Grimbizis GF, Tsalikis T, Mikos T, Papadopoulos N, Tarlatzis BC, Bontis JN. Successful end-to-end cervico-cervical anastomosis in a patient with congenital cervical fragmentation: case report. Hum Reprod. 2004;19(5):1204-10. http://dx.doi.org/10.1093/ humrep/deh213. PMid:15070881.

10. Scibilia G, Pecorino B, Pagano I, Scollo P. Case Report: Laparoscopic uterovaginal anastomosis for congenital isolated cervical agenesis. J Minim Invasive Gynecol. 2017;24(4):677-82. http://dx.doi.org/10.1016/j.jmig.2016.12.031. PMid:28254679.

11. Padmawar A, Syed R, Naval S. Laparoscopic uterovaginal anastomosis for cervical agenesis: A Case Report. J Minim Invasive Gynecol. 2018;25(2):334-5. http://dx.doi.org/10.1016/j.jmig.2017.07.016. PMid:28751235.

12. Bugmann P, Amaudruz M, Hanquinet S, La Scala G, Birraux J, Le Coultre C. Uterocervicoplasty with a bladder mucosa layer for the treatment of complete cervical agenesis. Fertil Steril. 2002;77(4):831-5. http://dx.doi.org/10.1016/S0015-0282(01)03269-1. PMid:11937142.

13. Daraï E, Ballester M, Bazot M, Paniel BJ. Laparoscopic-assisted uterovaginal anastomosis for uterine cervix atresia with partial vaginal aplasia. J Minim Invasive Gynecol. 2009;16(1):92-4. http://dx.doi.org/10.1016/j.jmig.2008.09.617. PMid:19110189.

14. Zhang Y, Chen Y, Hua K. Outcomes in patients undergoing robotic reconstructive uterovaginal anastomosis of congenital cervical and vaginal atresia. Int J Med Robot. 2017;13(3):e1821. http://dx.doi.org/10.1002/rcs.1821. PMid:28371283.

15. Zhang Y, Chen Y, Hua K. Robotic-assisted Reconstruction of the Cervix and Vagina by Small Intestinal Submucosa Graft and Fusion of the Hemiuterus. J Minim Invasive Gynecol. 2017;24(4):525-8. http://dx.doi.org/10.1016/j.jmig.2016.09.016. PMid:27702705.

16. Parsons JH, Bolton VN, Wilson L, Campbell S. Pregnancies following in vitro fertilization and ultrasound-directed surgical embryo transfer by perurethral and transvaginal techniques. Fertil Steril. 1987;48(4):691-3. http://dx.doi.org/10.1016/S0015-0282(16)59489-8. PMid:3308521.

17. Kato O, Takatsuka R, Asch RH. Transvaginal-transmyometrial embryo transfer: the Towako method; experiences of 104 cases. Fertil Steril. 1993;59(1):51-3. http://dx.doi.org/10.1016/S0015-0282(16)55613-1. PMid:8419221.

18. $\mathrm{Xu} \mathrm{C}, \mathrm{Xu} \mathrm{J,} \mathrm{Gao} \mathrm{H,} \mathrm{Huang} \mathrm{H.} \mathrm{Triplet} \mathrm{pregnancy} \mathrm{and} \mathrm{successful} \mathrm{twin} \mathrm{delivery} \mathrm{in} \mathrm{a} \mathrm{patient} \mathrm{with} \mathrm{congenital} \mathrm{cervical} \mathrm{atresia} \mathrm{who}$ underwent transmyometrial embryo transfer and multifetal pregnancy reduction. Fertil Steril. 2009;91(5):1958.

19. Huberlant S, Tailland ML, Poirey S, Mousty E, Ripart-Neveu S, Mares P, et al. Congenital cervical agenesis: Pregnancy after transmyometrial embryo transfer. J Gynecol Obstet Biol Reprod (Paris). 2014;43(7):521-5. http://dx.doi.org/10.1016/j. jgyn.2013.12.011. PMid:24842642.

20. Lin TK, Lin YR, Lai TH, Lee FK, Su JT, Lo HC. Transmyometrial blastocyst transfer in a patient with congenital cervical atresia. Taiwan J Obstet Gynecol. 2010;49(3):366-9. http://dx.doi.org/10.1016/S1028-4559(10)60077-0. PMid:21056327.

21. Anttila L, Penttilä TA, Suikkari AM. Successful pregnancy after in-vitro fertilization and transmyometrial embryo transfer in a patient with congenital atresia of cervix: case report. Hum Reprod. 1999;14(6):1647-9. http://dx.doi.org/10.1093/humrep/14.6.1647. PMid:10357993.

22. Thijssen RF, Hollanders JM, Willemsen WN, van der Heyden PM, van Dongen PW, Rolland R. Successful pregnancy after ZIFT in a patient with congenital cervical atresia. Obstet Gynecol. 1990;76(5 Pt 2):902-4. PMid:2216251.

23. Lai TH, Wu MH, Hung KH, Cheng YC, Chang FM. Successful pregnancy by transmyometrial and transtubal embryo transfer after IVF in a patient with congenital cervical atresia who underwent uterovaginal canalization during Caesarean section: Case report. Hum Reprod. 2001;16(2):268-71. http://dx.doi.org/10.1093/humrep/16.2.268. PMid:11157818.

\author{
*Correspondence \\ Marta Ribeiro Hentschke \\ Hospital São Lucas, Pontifícia Universidade Católica do Rio Grande do Sul \\ Av. Ipiranga, 6690, $2^{\circ}$ Andar, Laboratório 19 \\ CEP 90610-000, Porto Alegre, RS, Brasil \\ E-mail: martarh@yahoo.com.br
}




\section{Author information}

ALFS, Medical student. Pontifícia Universidade Católica do Rio Grande do Sul, Porto Alegre, RS, Brasil. MRH, MD, PhD. Pontifícia Universidade Católica do Rio Grande do Sul, Porto Alegre, RS, Brasil. MW, MD. Pontifícia Universidade Católica do Rio Grande do Sul, Porto Alegre, RS, Brasil. LMK, MD. Pontifícia Universidade Católica do Rio Grande do Sul, Porto Alegre, RS, Brasil. CSB, MD. Pontifícia Universidade Católica do Rio Grande do Sul, Porto Alegre, RS, Brasil. VDT, MD and MsC. Pontifícia Universidade Católica do Rio Grande do Sul, Porto Alegre, RS, Brasil. MM, MD and MsC. Pontifícia Universidade Católica do Rio Grande do Sul, Porto Alegre, RS, Brasil. ACB, MD and MsC. Pontifícia Universidade Católica do Rio Grande do Sul, Porto Alegre, RS, Brasil. AA, MD, PhD. Pontifícia Universidade Católica do Rio Grande do Sul, Porto Alegre, RS, Brasil.

\section{Authors contribution}

ALFS substantial contributions to conception and design. MRH critical review of the intellectual content; final approval of the version to be published. MW substantial contributions to conception and design. LMK critical review of the intellectual content. CSB substantial contributions to conception and design. VDT critical review of the intellectual content. MM critical review of the intellectual content. ACB critical review of the intellectual content. AA critical review of the intellectual content; final approval of the version to be published. 